\title{
A TEMÁTICA DA RELIGIÃO NO CONTEXTO DA GEOGRAFIA CULTURAL $^{1}$
}

\section{LA TEMÁTICA DE LA RELIGIÓN EN EL CONTEXTO DE LA GEOGRAFÍA CULTURAL}

\author{
Débora Vanessa Régis Ferreira SAMPAIO² \\ Tarcísio VANDERLINDE ${ }^{3}$
}

\begin{abstract}
Resumo: O presente artigo tem como objetivo discutir o estado da arte sobre o nascimento da geografia cultural e sua renovação, bem como o incremento da religião enquanto eixo temático de interesse dessa especificidade geográfica. Tem ainda por finalidade reconhecer o conteúdo no âmbito de pesquisa particular. Para atingir os objetivos propostos utilizou-se do método gabinete para realizar uma busca bibliográfica amparada em autores da ciência geográfica e afins que desenvolvem aportes teóricos voltados à temática. Diante da problemática apresentada, o artigo se estruturou em dois momentos: no primeiro se discorreu acerca do tema "A geografia cultural e seus fundamentos" e no segundo são realizadas análises sobre "A geografia da religião e o elo entre as duas ciências geografia e religião". No contexto, compreende-se que a temática discutida caracteriza-se como recorte de clássicos e seus estudos complexos, apresentando-se com um formato introdutório sob o ponto de vista acadêmico.
\end{abstract}

Palavras-chave: Geografia cultural, geografia da religião, reflexão histórico-geográfica.

Resumen: El presente artículo tiene como meta discutir el estado del arte sobre el nacimiento de la geografía cultural y su renovación, así como el incremiento de la religión como eje temático de interés de esa especificidad geográfica. También tiene por objeto reconocer el contenido en el ámbito de investigación particular. Para alcanzar los objectivos propuestos se utilizó el método gabinete para realizar una búsqueda bibliográfica amparada en autores de la ciencia geográfica y afines de desarrollan aportes teóricos orientados a la temática. En el primero se discutía acerca del tema "La geografía cultural y sus fundamientos", en el segundo, se realizan análisis sobre "La geografía de la religión y el elo entre las dos ciencias - geografía y la religión". En el contexto se comprende que la temática discutida se caracteriza como recorte de clásicos y sus estudios complejos, presentándose con un formato introductorio desde el punto de vista académico.

Palabras-clave: Geografía cultural, geografía de la religión, reflexión histórico-geográfica.

\section{Introdução}

O objetivo principal do artigo é discutir o estado da arte sobre o contexto geral do nascimento da geografia cultural e sua renovação, bem como o desdobramento da religião enquanto eixo temático de interesse da geografia cultural. A motivação em realizar o trabalho surgiu do intuito de conhecer e entender a geografia da religião no âmbito da geografia cultural.

\footnotetext{
${ }^{1}$ Este artigo é parte de uma pesquisa de mestrado finalizada, executada com recursos da Coordenação de Aperfeiçoamento de Pessoal de Nível Superior (Capes) e Fundação Araucária.

${ }^{2}$ Mestre pelo Programa de Pós-Graduação em Geografia - PPGG/MCRONDON - Universidade Estadual do Oeste do Paraná. Marechal Cândido Rondon, PR; deboravanessarf@gmail.com.

${ }^{3}$ Docente do Programa de Pós-Graduação em Geografia - PPGG/MCRONDON - Universidade Estadual do Oeste do Paraná. Marechal Cândido Rondon, PR; tarcisiovanderlinde@ gmail.com.
} 
Transpondo algumas décadas, a geografia cultural buscou firmar-se em uma estrutura sólida, caracterizando-se como um procedimento científico em pesquisas. Com um olhar democrático, propõe discutir outras possibilidades de entender o espaço geográfico e as relações sociais intermediadas pela religião, pois são os atos coletivos ou individuais que afirmam e expressam as mais diversas características culturais de uma sociedade, cabendo à geografia as tarefas de compreender e esclarecer como as manifestações religiosas ressignificam os espaços. Conforme Rosendahl (2003, p.9),“[...] as práticas religiosas imprimem na paisagem marcas fortemente relacionadas com os aspectos culturais da comunidade, de tal modo que o espaço pode ser percebido de acordo com os valores simbólicos que ali estão representados".

Para o desenvolvimento do artigo foi realizado um mapeamento no campo conceitual e histórico do pensamento geográfico, o qual substantiva a base de compreensão conteudística que metodologicamente se constituiu pela prática de pesquisa "gabinete". Na sondagem foram realizados levantamentos bibliográficos, elencados e selecionados livros, artigos científicos, periódicos e publicações dinâmicas a exemplo de revistas, visando auxiliar no aprofundamento e estruturação conceitual da temática pesquisada.

No artigo são apresentados dois principais momentos. O primeiro, "A geografia cultural: alguns fundamentos",aborda de maneira conceitual como se deu o processo de formação da geografia cultural e como essa se tornou um subcampo da ciência geográfica. São aí introduzidos os arranjos históricos do pensamento geográfico e epistemológico. As explicações envolvem desde a geografia moderna até as discussões atualizadas do século XXI.O segundo tem como temática "A geografia da religião e o elo entre as duas ciências: geografia e religião". Nele se discute e se reflete, sob o olhar da geografia cultural, a trajetória da geografia da religião, desde os primeiros contatos entre ciências aos entraves epistemológicos, chegando ao período de reconhecimento, quando a geografia da religião é assumida pela originalidade e seriedade para discutir relações e produção espacial no contexto homem-espaço-religião e cultura.

O objeto foi tangenciado frente à conceituação e ao entendimento de pensadores como Carl Sauer, Daniel Gade, David Sopher, Denis Cosgrove, Émile Durkheim, Clifford Geertz, Sylvio Fausto Gil Filho, James Duncan, Marvin Mikesell, Mircea Eliade, Paul Claval, Paul Fickeler, Peter Berger, Philip Wagner, Roberto Corrêa, Ruy Morreira, Werther Holzer, Willian Speth e Zeny Rosendahl. Tais autores trazem em suas produções bases científicas abastadas para as discussões dos tópicos acima mencionados.

No contexto, compreende-se que a temática discutida fornece um recorte de grandes clássicos e seus estudos complexos, apresentando-se com um formato básico e introdutório, porém pertinente sob o ponto de vista das ferramentas a serem utilizadas em pesquisas acadêmicas.

\section{A geografia cultural: alguns fundamentos}

A geografia cultural denota-se como um subcampo expressivo da ciência geográfica, mas a abordagem cultural na geografia passou por ciclos evolutivos e complementares. Tais dinâmicas aconteceram sincronicamente a uma engrenagem de dimensões maiores da disciplina, relacionadas à busca de método e doutrina, bem como do seu objeto de estudo.

Na perspectiva de Sauer (2011), é evidente, ao decorrer da evolução da ciência, que a geografia moderna se responsabilizou por uma subdivisão dos interesses geográficos entre os grupos da geografia humana e cultural, limitando a unidade nas suas objetivações. Apesar de ambas se desenvolverem no mesmo período, cada uma surgiu com um ponto de partida, por vezes, pouco conciliáveis entre si. 
Ao final do século XIX, na Europa, surgiam as bases da dimensão cultural, marcadas por uma aguçada curiosidade científica e pela diversidade das sociedades desde suas línguas, técnicas, obras e princípios morais (CLAVAL, 2011). Essa geografia buscava na cultura material e na análise entre gêneros de vida e paisagens rústicas conteúdos básicos para o seu desenvolvimento (CLAVAL, 2002).

Naquele século, grande parte dos geógrafos comungava do alicerce científico naturalista, o qual deu apoio ao princípio que o ambiente, mediante suas leis, explicava absolutamente a sociedade e, por conseguinte, a cultura. A partir dessa realidade se empreendeu uma inclinação por uma geografia de conteúdos regidos pela ação da natureza, com objeção negativa ao que estivesse à parte dessa concepção científica. Suas premissas negavam o estudo das dimensões psicológicas ou mentais da cultura, mas aprovavam o desenvolvimento disciplinar sob a ótica do evolucionismo (CLAVAL 2002, 2011a).

Com o olhar contemporâneo, compreende-se que era compartilhado o uso da cultura em seu aspecto reducionista, fomentado pelos ditames de alguns representantes da disseminação doutrinária. Ao instante que a comunidade científica, em particular a geográfica, tornou-se livre do "fundamentalismo" religioso, imposto por uma sociedade teocêntrica, automaticamente foi fisgado por uma doutrina de afirmações racionais formuladas por uma elite pensante, o que talvez obscureceu por décadas conteúdos de ordem imaterial e subjetiva em função da formulação dos dados objetivos originários da ordem física.

Nesse contexto, o entendimento evolucionista darwiniano influenciou diretamente o desenvolvimento da geografia humana sob o elo homem e seu ambiente, evidenciado por Friedrich Ratzel na obra "Antropogeografia". Apesar da ênfase ambientalista e de afirmações áridas nessa produção, o alemão também se propôs discutir o estudo da cultura, voltado para a mobilidade populacional, condições de assentamento humano e difusão da cultura, porém geógrafos ocidentais disseminaram em maior proporção a faceta ambientalista de suas obras, visto a atmosfera preponderante do positivismo (SAUER, 2011).

Imersa nesse movimento, a geografia francesa vidaliana aderiu ativamente aos resultados pautados na ecologia, através da ideia de gênero de vida (CLAVAL, 2011a). A partir de então, iniciou-se timidamente uma abordagem cultural, cujo foco limitava-se às técnicas e hábitos utilizados pelos grupos humanos. Na visão vidaliana, houve momentos que o discurso direcionou para fatores culturais, a exemplo dos aspectos da religião, contudo a análise mais sensível centrou-se estritamente nas edificações estruturais de igrejas, expondo templos e mesquitas, bem como na abordagem das tradições e interdições do que por ventura era negado ou permitido de acordo com a regra de fé (CLAVAL, 2011b).

Um novo momento surge com a geografia cultural norte-americana em 1923, quando a universidade da Califórnia, campus de Berkeley, recebeu Carl Ortwin Sauer, um professor transferido da universidade de Michigan e que tinha como objetivo desenvolver sua carreira enquanto geógrafo. Ele se dispôs a apresentar um formato particular para pesquisar a ciência geográfica e, visto sua projeção, por ser um exemplo de profissional, socrático, erudito e que se negou a replicar e reproduzir as abordagens recorrentes para responder seus questionamentos geográficos, foi eleito honrosamente o geógrafo norte-americano de maior importância do século XX (GADE, 2011).

Segundo Corrêa e Rosendahl (2011), a escola de Berkeley teve um papel fundamental para a geografia cultural e principalmente a norte-americana, pois representou o primeiro start no desenvolvimento e disseminação de conteúdo intelectual da área.

Tornando-se o principal fomentador desse campo de pesquisa, o professor e fundador da escola sauariana introduziu as intervenções iniciais para os estudos da geografia cultural, privilegiando a paisagem cultural. Dentre tantas produções autorais, a mais citada foi o ensaio "Amorfologia da paisagem" (MOREIRA, 2008). Essa abordagem colocou em destaque a 
impressão humana na Terra, rompendo o enfoque então preponderante do determinismo do meio ambiente (GADE, 2011). Nesse caso, ele não ficou apenas na afirmação recorrente de que o ambiente era o meio influenciador do homem; observou que a cultura do homem, de certa forma, exercia seu poder de transformação sobre o meio e comprimiu em seus estudos tendências estéticas e filosóficas, empíricas e éticas do historicismo (SPETH, 2011).

A morfologia da paisagem apresentada por Sauer não estava puramente vinculada ao aspecto orgânico, mas sob a influência da cultura. "A cultura é o agente; a área natural, o meio; e a paisagem cultural, o resultado" (SAUER, 2012, p. 69).

Contribuindo para o raciocínio de Sauer sobre cultura, os seus discípulos Philip Wagner e Marvin Mikesell (2011, p.27) apresentaram que:

Os aspectos da Terra, em particular aqueles produzidos ou modificados pela ação humana, são de grande significado. O estudo destes aspectos geográficos resultantes da ação do homem considera as diferenças entre as comunidades humanas que as criam ou criaram e se refere aos modos especiais de vida de cada uma como culturas.

Em outras palavras, a cultura torna-se como um código a ser decodificado e quando entendida suas ligações e interligações, características humanas de semelhanças e dessemelhanças são expressas a partir dela. Seguindo esse preceito de cultura, áreas foram rotuladas mediante os atributos identificados pelas comunidades humanas nas quais residem.

Baseado nessas discussões, esse período precedeu o processo de revisão e renovação dos conceitos de cultura utilizados pelos geógrafos. Analisando temporalmente a trajetória da geografia cultural, que ultrapassa os 100 anos de história do pensamento geográfico, Corrêa e Rosendahl (2012) desmembraram a geografia cultural em duas vertentes essenciais, sendo a primeira com a geografia cultural sauariana, estruturada no historicismo, que enfatizava a diversidade cultural, buscando a compreensão do presente tempo sob o aspecto de valorização do passado (CORRÊA e ROSENDAHL, 2011). De acordo com Wagner e Mikesell (2011), as propostas apresentadas enveredaram a disciplina por cinco ramificações de estudo: cultura, área cultural, paisagem cultural, história da cultura e ecologia cultural.

A segunda vertente refere-se à geografia cultural pós-1980, que será tratada adiante. Corrêa e Rosendahl (2012) propõem ainda que a diferença entre essas duas geografias está basicamente em três domínios: a gênese, o percurso e o conceito de cultura.

Percorrendo as fases de evolução e retração da geografia cultural, ancoramos a leitura no final da década de 1960 e na primeira metade de 1970, tempo em que a nova geografiaobscureceu a presença da geografia cultural, tornando incipientes suas explicações por meio da cultura, visto as mudanças e modernizações que a sociedade enfrentava. "[...] A preferência mudou dos estudos sobre paisagens culturais, habitat rural, sistemas agrícolas e difusão cultural para estudos sobre lógicas locacionais e estudos urbanos, entre outros" (CORRÊA, 2009, p. 2).

A obstinação entre os geógrafos estava em encontrar um instrumento metodológico para explicar os novos processos e interrogações ocorrentes. Essa situação estremeceu intensamente o caminhar dessa subdisciplina, tanto na Europa quanto nos Estados Unidos, e as repreensões críticas metodológicas permeavam desde a linha teórico-quantitativa ao materialismo histórico e dialético. Conforme Claval (1999, p.48), “[...] a geografia cultural entrou em declínio porque desapareceu a pertinência dos fatos de cultura para explicar a diversidade das distribuições humanas", tendo em vista que as explicações via cultura se apoiavam na concepção transcendental da entidade supraorgânica e pelo enquadramento dos estudos do determinismo cultural. 
Holzer (2012) esclarece que mesmo que a geografia cultural estivesse retraída pelaascensão da geografia quantitativa e pelo aparecimento da geografia comportamental, geógrafos da linha cultural e humanística buscaram restaurar e recolocar essa geografia que estava sendo descartada. Primeiramente com David Lowenthal e posteriormente com Yi-Fu Tuan, ambos com método filosófico de investigação alternativo.

A discussão por ele proposta desviava-se do eixo então dominante, o da procura de metodologias que se adequassem aos modelos matemáticos, remetendo-se para a fundamentação de uma teoria de conhecimento geográfico. Seu ponto de partida era a "geosofia", vista à base de um projeto de ciência que abarcasse os vários modelos de observação, consciente e o inconsciente, o objetivo e o subjetivo, o fortuito e o deliberado, o literal e o esquemático. (HOLZER, 2012, p. 166)

Na perspectiva de Tuan, a geografia deveria aderir aos novos paradigmas, favorecendo os estudos das vivências, que se projetam de um lugar particular, a exemplo do lar, para as paisagens mais globais, de uma paisagem humanizada para outra mais primitiva (HOLZER, 2012). Sobre as experiências dos lugares, ele aborda a particularidade de sentimentos, visto suas experiências de viagens (CLAVAL, 2011a). Essas afirmações conceituais criadas por esses e outros autores imbuíram todo o movimento vindouro da geografia cultural.

Segundo Claval (2011a), aderir aos novos horizontes partia da necessidade de uma melhor compreensão da escola francesa e seus desígnios, como também das alterações realizadas nas orientações humanista e radical da geografia inglesa e americana.

O processo de despertar para uma nova dimensão cultural na geografia passou a ser evidenciado após a prefixação de alguns princípios. O primeiro é evidenciado quando o conceito de cultura foi retomado dentro da linha da geografia cultural, opondo-seàs concepções antropológicas criadas por Edward Tylor no ano de 1871 (CLAVAL, 2011; CORRÊAA, 2011), e posteriormente com a crítica aos discípulos que faziam uso da definição de cultura autônoma e abrangente desenvolvida pelo antropólogo Alfred Kroeber (DUNCAN, 2011).

[...]A década de 1970 foi, em realidade, uma arena de embates epistemológicos, teóricos e metodológicos, no âmbito dos quais emergem uma geografia crítica e diferentes subcampos que, nos anos 80, iriam confluir, em parte, para gerar a denominada geografia cultural renovada. A década de 1980 vê configurar-se esta nova versão da geografia cultural. (CORRÊA, 2009, p.2)

Muitas das concepções preestabelecidas estavam sendo desmistificadas, avaliadas e reinterpretadas. Algumas referiam-se exatamente ao conceito abrangente de cultura, paisagem cultural, objetivos e método de análise de pesquisa disseminado por Sauer. Romper com a interpretação da paisagem cultural torna-se um exemplo, pois esse compreendia que a cultura tomava o lugar da centralidade, passando a se manifestar como o agente transformador da paisagem natural (CORRÊA, 2014).

Buscando uma conotação significativa, as críticas revelaram serem contra a percepção cultural apresentada como uma entidade superior ao homem, a qual torna-se autoexplicativa em suas normas (DUNCAN, 2011). Ou seja, não bastava entender "[...] a cultura como entidade abstrata, supraorgânica, sem agentes sociais concretos, sendo gerado um quadro harmonioso: a paisagem cultural [...]" (CORRÊA, 2014, p.41), pois o significado da paisagem possui realidades simbólicas. 
O contraponto dos estudos focados no conceito de cultura então desenvolvidosurge efetivamente nadécada de 1970. Com uma nova interpretação para essa temática, a geografia inglesa eleva o nome de Denis Cosgrove, o qual se propôs trabalhar e trilhar numa perspectiva marxista esse conceito, cuja escolha ocorreu por influências acadêmicas.

O conceito de cultura tinha para Cosgrove outras raízes e configurações. Com base em Cassirer, noCentre for Contemporary Cultural Studies da Universidade de Birmingham, dirigido na década de 1970 por Stuart Hall, de Raymond Williams, professor na Universidade de Oxford, e na antropologia interpretativa de Clifford Geertz, cultura era entendida como os significados elaborados e reelaborados pelos diferentes grupos sociais a respeito das diversas esferas da vida. (CORRÊA, 2014, p. 40)

Baseados em suas convicções científicas, Cosgrove e Peter Jackson fazem uma conceituação para a insurgência da geografia cultural desse momento:

Uma possível definição dessa "nova" geografia cultural seria: contemporânea e histórica (mas sempre contextualizada e apoiada na teoria); social e espacial (mas não reduzida a aspectos da paisagem definidos de forma restrita); urbana e rural; atenta à natureza contingente da cultura, às ideologias dominantes e às formas de resistência. Para essa "nova" geografia a cultura não é uma categoria residual, mas o meio pelo qual a mudança social é experienciada, contestada e construída. (COSGROVE \& JACKSON, 2011, p. 136)

Como autor âncora da antropologia, que contribuiu sobremaneira para a geografia nesse momento de ebulição científica, em relação ao conceito de cultura,Geertz, na obra "A interpretação das culturas", pôde reforçar o entendimento da diversidade cultural e acrescentar a possibilidade em elencar diversas maneiras que obscureçam o sentido conceitual da cultura, todaviaalertou que tal ato conduz a uma simplificação, empobrecendo essa concepção de estudo.

[...] Uma delas é imaginar que a cultura é uma realidade "supraorgânica" autocontida, com forças e propósitos em si mesma, isto é, reificá-la. Outra é alegar que ela consiste no padrão bruto de acontecimentos comportamentais que de fato observamos ocorrer em uma ou outra comunidade identificável isso significa reduzi-la. (GEERTZ, 2008, p. 8)

No caso, o significado da cultura e da análise das paisagens passou a ser reconduzido nas explicações geográficas. A princípio tudo era esclarecido por meio da cultura material, porém cresceu a importância dessa ser explicada segundo as mudanças que ocorriam na sociedade, a exemplo do enraizamento do capitalismo e todos seus resultados impressos no organismo social. A abordagem contemporânea firma-se na ideia de que o homem é um agente ativo e que a cultura não está à parte desse indivíduo, mas intrinsecamente relacionada a ele, desde costumes e princípios. A cultura deve ser analisada como parte das construções sociais. Cosgrove\&Jackson (2011, p.142) afirmam que "[...] as culturas são contestadas politicamente. A visão unitária de cultura dá lugar à pluralidade de culturas, cada uma com suas especificidades de tempo e lugar".

A partir desse olhar, Corrêa (2011a, p. 170) expõe que "[...] a diversidade cultural não pode ser restrita às convencionais diferenças raciais, étnicas, linguísticas ou religiosas". Para Geertz (2008), quando o conceito de cultura delineia formas, torna-se limitado, pois age 
especificando, sufocando e representando uma análise não esclarecedora, apontando que não é adequado elaborar uma "Teoria Geral de Interpretação Cultural"

[...] O homem é um animal amarrado a teias de significados que ele mesmo teceu, assumo a cultura como sendo essas teias e a sua análise; portanto não como uma ciência experimental em busca de leis, mas como uma ciência interpretativa à procura do significado. (GEERTZ, 2008, p.4)

Cada grupo social produz cultura, e essa são várias, e podem ser recriadas, heterogêneas e variantes.

$\mathrm{Na}$ geografia, em uma escala gradual de correntes, entende-se que a diretriz do pensamento clássico progressista não foi capaz de sanar ou explicar as dúvidas recorrentes do século XIX e XX, muito embora tinha seu valor. Ao longo da busca por um rumo, a geografia foi apresentada à corrente do pensamento radical crítico com o objetivo de situar essa ciência na realidade econômica, social e política. Toda essa movimentação colaborou para que o espaço de discussões ficasse aberto para o surgimento de novas intervenções epistemológicas.

Essas reflexões acerca do quadro epistemológico permitiram dar abertura para a subjetividade humana no campo das pesquisas nas ciências sociais, potencializando o processo da virada cultural. A ressurreição da ordem fenomenológica reencontra ideologias ligadas às experiências dos homens no meio social e ambiental e compreendea significação que estes impõem ao ambiente no sentido dado às suas vidas e à diversidade (CLAVAL, 2011).

[...] A corrente nova parece virar as costas à atualidade: volta-se para as lembranças de infância e a maneira como modelam a sensibilidade das pessoas; fala-se daquilo que dá charme às paisagens; descobre-se a festa, o espetáculo. (CLAVAL, 2011a, p.221)

Esse novo momento da geografia trouxe novas perspectivas e paradigmas de análise, dando ao indivíduo a possibilidade dese apresentar a partir da sua história de vida, contemplando a percepção que tem do mundo por meio da construção que faz do lugar onde produz suas relações, envolvendo suas convicções religiosas (ROSENDAHL, 1996).

Corrêa \&Rosendahl (2012) consideram a geografia cultural um conhecimento heterotópico, pois tem a capacidade de se enraizar por diferentes horizontes a partir de uma base, sendo que nenhuma dessas zonas de ramificação, por mais plural que seja, pode se sentir superior à outra, já que essa diversidade caracteriza uma cultura aberta, sujeita a uma amplitude no campo de investigação.

\section{A geografia da religião e o elo entre as duas ciências: geografia e religião}

De imediato, relacionar religião com geografia parece uma tarefa não científica e distante de concretização. Elas eram apresentadas como "substâncias" de densidade, estrutura e polaridades diferenciadas ${ }^{5}$, porém, ao longo do tempo, pesquisas nessas áreas apontaram inter-relações entre ambas. Fickeler (2008, p.7) menciona que "[...] religião e geografia

\footnotetext{
${ }^{4}$ Termo usado por Geertz no livro "A interpretação das culturas" (2008).

${ }^{5}$ Remete a uma comparação simplista, mas com intuito didático, que é a relação entre a molécula da água e óleo.
} 
parecem, em princípio, ter pouquíssimos pontos de contato, o que também é reforçado pela forte concepção de que o reino de Deus está no meio de vós ${ }^{6 \%}$. Com a utilização do livro cristão, a bíblia, ele evidencia que o ato religioso depende de lugares para se realizar, e se realiza rotineiramente por toda a extensão terrestre. Tal fatotece relações entre as duas áreas de estudo e estende àciência geográficaa possibilidade de pesquisar fenômenos religiosos.

Rosendahl (1996, p. 11) destaca com fervor a sincronização entre essas ciências, contudo, vale ressaltar que a percepção a seguir é recente, visto todo o processo histórico geográfico da geografia da religião:

[...] A geografia e a religião são, em primeiro lugar, duas práticas sociais. $\mathrm{O}$ homem sempre fez geografia, mesmo que não soubesse ou reconhecesse formalmente a disciplina geografia. A religião, por outro lado, sempre foi parte integrante da vida do homem, como se fosse uma necessidade sua para entender a vida. Ambas, geografia e religião, encontram-se através da dimensão espacial, uma porque analisa o espaço, a outra porque, como fenômeno cultural, ocorre espacialmente.

Até chegarmos à real comunhão entre a geografia e a religião, retornaremos às fases iniciais, quando se praticavam as primeiras diretrizes desse enlace. Apesar do atraso, ou do processo evolutivo em a geografia entender que as relações de experiência entre o sujeito e a religião eram possíveis, Fickeler (2008) apontou que há anos existiam inúmeros trabalhos que retrataram as religiões e suas distribuições na área da geografia, entretanto o detalhe estava na prática de leitura dessas pesquisas, cujo método aliado era o descritivo, o qual dispensava interpretações subjetivas. "Originalmente, a geografia da religião foi organizada pelos historiadores da igreja, no estudo da geografia bíblica condicionado aos parâmetros teológicos, e não por geógrafos" (GIL FILHO, 2012, p.11).

Durante o século $\mathrm{X}$ foram desenvolvidas as produções geográficas precursoras que relacionavam espaço e religião. Dentre os responsáveis estavam a geografia grega, a geografia islâmica e as escolas monásticas da Irlanda. À frente desse ciclo produtivo surgiram lacunas de conhecimento geográfico religioso que só puderam ser retomadas na era da renascença. (PARK 1994 apud SILVA \& GIL FILHO, 2012). Esse momento histórico lançou inúmeras mudanças de ordem social, política, econômica, religiosa e cultural, colaborando para o despertarde novos estudos.

Logo após o século XVI, a relação feita entre geografia e religião estendeu suas raízes no período das conquistas de terras, cuja interferência da tradição cristã lança explicações ao homem sobre o "poder" de dominar a natureza. "Após a reforma e a contrarreforma, uma nova concepção de geografia se impõe: ela conta como o homem transformou a Terra para fazer dela realmente sua morada. A geografia torna-se uma ilustração de gênese"7 (CLAVAL, 2011a, p. 88).

É fato que a geografia da religião não surgiu ao acaso. Ela foi substantivada por inúmeras discussões epistemológicas, produções pontuadas, individualizadas e, por vezes, desconhecidas.

Compreende-se que muito antes dos anos de 1980 já se tinham obras que mencionavam as dimensões culturais religiosas, as quais podem ser consideradas peças importantes para a nova formatação dessa ciência.

A partir de cada uma das obras remanescentes existem significados mediante o desenvolvimento científico em um dos ramos da geografia cultural, a geografia da religião. É

\footnotetext{
${ }^{6}$ Faz referência ao texto bíblico de Lucas - capítulo 17, versículo 21.

${ }^{7}$ Faz referência ao texto bíblico de Gênese - capítulo 1, versículos 26 a 30.
} 
sabido que antes da religião ser objeto de estudo da geografia, ela foi de outras ciências humanas, a exemplo da psicologia, antropologia, história e sociologia, nas quais apareceram a grande maioria de livros-textos que se permitiram preocupar-se com a experiência obtida dos sujeitos com a religião. Porém, cada ciência, inclusive a geográfica, buscou seu norte de investigação.

Para contextualizar, o quadro 1 exibe uma seleção de pesquisas que embasam e referenciam a geografia da religião de séculos passados ao século atual ${ }^{8}$.

\section{Quadro 1 - Obras fundamentais ${ }^{9}$}

\begin{tabular}{|c|c|c|}
\hline \multicolumn{3}{|c|}{ Algumasorientaçõesbibliográficas paraa geografiada religião } \\
\hline Autores & Obras & Ano \\
\hline Max Weber & "Gesammelte Aufsätzezur Religions soziologie" & 1920 \\
\hline Paul Fickeler & "Grundfrangen der Religions geographie"b & 1947 \\
\hline Pierre Deffontaines & "Géographie dês Religions" & 1948 \\
\hline Eric Dardel & "L’ Homme et la Terre" & 1952 \\
\hline Émile Durkheim & "Les Formes Élémentaires de La Vie Religieuse" & 1959 \\
\hline Mircea Eliade & "O sagrado e o profano a essência das religiões" & 1962 \\
\hline David Sopher & "Geography of Religions" & 1967 \\
\hline Russell King & $\begin{array}{l}\text { "The pilgrimage to Mecca: some geographical and historical } \\
\text { aspects" }\end{array}$ & 1972 \\
\hline Yi-Fu Tuan & $\begin{array}{l}\text { "Topofilia: um estudo da percepção, atitudes e valores do meio } \\
\text { ambiente" }\end{array}$ & 1980 \\
\hline Peter Ludwig Berger & $\begin{array}{l}\text { "O dossel sagrado: elementos para uma teoria sociológica da } \\
\text { religião" }\end{array}$ & 1985 \\
\hline Manfred Büttner. et all. & $\begin{array}{l}\text { "Geographia Religionum. Interdisziplinäre Schriftenreihezur } \\
\text { Religions geographie" }\end{array}$ & 1985 \\
\hline Gilbert Rinschede & "Das PilgerzentrumLoudes" & 1985 \\
\hline Pierre Bourdieu & "A economia das trocas simbólicas" & 1987 \\
\hline Lily Kong & "Geography and Religion: trends and prospects" & 1990 \\
\hline Jackson, R. e Hudman L.E. & "Cultural Geography People, Place and Environment" & 1990 \\
\hline
\end{tabular}

Org. AUTOR

A produção de Fickeler provoca um debate sobre as influências concebidas entreambiente e religiosidade, ambos no aspecto geo-religioso. Sugere a hipótese de que "se o ambiente interfere na religiosidade, concomitantemente existe uma resposta sincrônica, a religiosidade passa a refletir sobre o ambiente" (FICKELER, 2008).

${ }^{8} \mathrm{O}$ quadro 1 tem por objetivo elencar cronologicamente algumas obras que influenciaram o processo de desenvolvimento da geografia cultural trazendo a temática da religião.

${ }^{9}$ As referências de autores, obras e anosforam catalogadas das leituras:

ROSENDAHL, Zeny. Bibliografia comentada. In: ROSENDAHL, Z. Espaço e religião: uma abordagem geográfica. Rio de Janeiro: UERJ - NEPEC, 1996.

ROSENDAHL, Zeny. Construindo a geografia da religião no Brasil.Espaço e Cultura.Rio de Janeiro, $\mathrm{n}^{\mathrm{o}} 15,2003$. 
Claval (2011b) aponta que Pierre Deffontaines tendenciou suas pesquisas para as manifestações visíveis da cultura na superfície terrestre. Visto a influência vidaliana, Deffontaines buscou, a partir das obras arquitetônicas, mostrar os símbolos religiosos.

Sopher apresenta como forma de estudo a interação espacial entre a cultura e seu ambiente terrestre complexo e a situação espacial entre diferentes culturas. Yi-Fu Tuan, por sua vez, propõe compreender os fenômenos além do visível, trazendo à baila o estudo do sagrado sob a introdução da experiência emocional do sobrenatural. Já Manfred Büttner sugeriu os aspectos geográficos social, teológico e o específico religioso-geográficointerdisciplinar, os quais sugerem orientações geográficas para o estudo da religião.

Com um aporte contextual sobre o desenvolvimento da religião como tema pertinente à geografia, Lily Kong ancorou suas produções.

Sobre o estudo das práticas de peregrinação nos santuários internacionais tem-se Russell King com o islamismo, Richard Jackson e Lloyd E. Hudman com o budismo e Gilbert Rinschede com o catolicismo. Esse fenômeno é estudado por três motivos básicos: por ser uma prática similar na maioria das religiões, representar umas das mais claras demonstrações de fé e está em diversas realidades culturais (ROSENDAHL, 2003).

Sob a ótica do sociólogo e teólogo Berger (1985) são percebidas as várias sociedades do mundo como um empreendimento em construção, e como parte desse empreendimento a religião se sobressai.

Quanto a Dardel, o enfoque é dado mediante a produção textual L'homme et la terra. Ele foi enfático em trazer para a geografia a necessidade de se descobrir o sentido da presença humana no plano terrestre, por meio do sentimento religioso, dos mitos e da dimensão transcendente de outros lugares (CLAVAL, 2011b).

Durkheim introduz como tema central de estudo o fenômeno religioso. Ele vê nas comunidades primitivas uma possibilidade aproximada de enxergar a essência social e com ela a religião. Seu entendimento sobre esse fenômeno aponta para a indução de uma consciência coletiva social (DURKHEIM, 2000). Já Mircea Eliade trata das concepções religiosas universais e primitivas, sobre a dicotomia dos espaços sagrado e profano e a relação do sujeito com o microcosmo.

Retomando a discussão, Rosendahl (1996, p.19) explica que o primeiro e não desmerecido campo geográfico religioso se propôs a realizar leituras de acordo com a essência da época.

Os geógrafos, preocupados em analisar as paisagens, abordaram durante muito tempo os fatos religiosos pela periferia. Entretanto, afirma-se que eles são capazes de dar contribuições geográficas efetivas e inovadoras aos estudos da religião, penetrando profundamente no pensamento e maneiras de um sistema religioso ou no estudo de temas como imagens e simbolismo, valor e significado, conflito e compromisso.

Por ser amplamente influenciada pelo pensamento positivista, a geografia desconhecia as relações sociais e tinha o homem como um "objeto" da paisagem, apenas. O ser humano foi caracterizado pelas relações factuais.

[...] O tema da religião era negligenciado: o positivismo caracteriza-se por um agnosticismo no qual nega à razão e à fé o poder de provar a existência de Deus. Tudo que transcende o plano dos sentidos é inacessível ao conhecimento humano e, portanto, não demonstrável. A existência de Deus constitui-se em uma questão metafísica, fora do âmbito da ciência positiva. (ROSENDAHL, 1996, p. 20) 
Outra matriz do pensamento geográfico que desvalorizou a concepção religiosa foi a geografia crítica, pois, sob a influência do materialismo histórico e dialético, bitolou sua retórica nas lutas de classes entre proletariado e burgueses, processo produtivo, ou seja, em todo universo que representasse o modo de produção capitalista. “[...] É possível dizer que a geografia no Brasil, na década de 1980, esteve excessivamente influenciada pelo materialismo histórico e dialético aprendido, em muitos casos, de forma superficial e com equívocos" (ROSENDAHL, 2010, p.12). Discutindo sobre o período de influência marxista na geografia, Rosendahl afirma:

A reflexão teórica marxista foi aplicada aos problemas sociais e aos de ação política de transformação da sociedade em direção ao socialismo. O procedimento rigorosamente materialista de análise em busca de novas forças que realmente moviam a sociedade levou os geógrafos críticos a marginalizar as questões religiosas de seus estudos. Em realidade, o materialismo histórico e dialético é ateu, isto é, diferentemente de considerar a existência de Deus uma questão científica, como no positivismo, admite plenamente, com base na visão materialista, a inexistência de Deus. (ROSENDAHL, 1996, p. 22)

Nos embalos das diversas possibilidades de pesquisa, a temática emudecida na geografia tradicional e avivada na virada cultural foi a sacrorreligiosa, que, apesar de ecoar antes da renovação ou evolução da geografia dos nos 1980, por décadas foi ignorada e quando estudada colocada sob a ótica do visível, palpável e objetivo. Segundo Claval (2011b, p. 148),

[...] A disciplina não tinha que estudar a dimensão mental dos comportamentos humanos. Por exemplo, os geógrafos sabiam que a religião tinha um papel importante na geografia, mas eles nunca falavam da fé, das crenças, porque são fenômenos mentais.

Quando a virada cultural emergiu, o objetivo de se perceber as relações a partir do prisma acima mencionado por Claval foi dissipado. A proposta estava em dispor as diferentes possibilidades de análise, descapsulando as práticas remanescentes, que determinavam alguns resultados e métodos únicos como sendo verdades absolutas.

O empenho da geografia humanística trouxe novas perspectivas de análise da geografia da religião, relegando as abordagens puramente funcional e quantitativa e aproximando as posições qualitativas de ordem sobrenatural, compreendidas por Corrêa e Rosendahl (2012) como de natureza da experiência religiosa e das formas que essas assumem o espaço. Apoiada nesse direcionamento, a geografia da religião se empoderou de outros anversos de análise para o desenvolvimento de uma nova fase.

[...] Os geógrafos da religião ganham ânimo em penetrar em esferas potencialmente férteis, embora ainda não conquistadas, principalmente no Brasil, de compreender o sentido que a realidade dá à razão humana, bem como a vivência e a prática religiosa como caracterizadoras dos espaços geográficos. (ROSENDAHL, 1996, p. 24)

O entrosamento da geografia acadêmica brasileira ${ }^{10}$ com a produção cultural religiosa contemporizou 60 anos. Todo esse período tem motivos firmados na influência da escola

\footnotetext{
${ }^{10} \mathrm{O}$ primeiro departamento de geografia foi criado em 1934 na Universidade de São Paulo.
} 
francesa, a qual se constituía como sendo a inspiração da geografia do Brasil. Sobre os conteúdos culturais religiosos, esses propositadamente eram inibidos nos estudos regionais.

Como reflexo da lenta ascensão de uma geografia humanizada na década de 1970, as cátedras brasileiras com muita sutileza encaminharam produções acadêmicas na área da geografia cultural. Iniciou-se pioneiramente no ano de 1972, com a pesquisa vanguarda no âmbito geográfico religioso, intitulado: "Pequenos centros paulistas de função religiosa", realizada por Maria Cecília França, para título de doutoramento na USP. Com um tema inédito, França foi influenciada pela perspectiva do impacto religioso sobre a paisagem nas cidades de Iguape, Bom Jesus dos Perdões e Pirapora do Bom Jesus.

Depois, com a tradução do clássico livro de Claude Raffestin "Por uma geografia de poder" de 1980, Cecília colaborou com a disseminação da importante discussão teórica entre religião e poder na geografia e, por conseguinte no subcampo da geografia da religião. $\mathrm{O}$ clássico atentou para alguns aspectos outrora apenas materializado pela geografia francesa. Abase crítica manifestou entre outros assuntos a relação de poder de Estados e religiões e a luta para incorporação das incursões laica.

No Brasil e fora dele, ao final do século XX e início do século XXI, núcleos de pesquisa, a exemplo do Núcleo de Estudos e Pesquisa sobre o Espaço e Cultura (Nepec) e do Núcleo Paranaense de Pesquisa em Religião (Nupper) ${ }^{11}$, revistas, congressos e encontros ganharam notoriedade e expressividade com a disseminação da religião sob o aspecto cultural da geografia.

De acordo com Rosendahl (2010, p.11), a contribuição inicial do núcleo em inserir a geografia cultural no Brasil ocorreu em três eixos temáticos de investigação: espaço e religião, espaço e cultura popular e espaço e simbolismo. Os anos 1990 se constituíram como um divisor de águas, marcados por algumas investidas na produção bibliográfica e ousadas propostas de estudo: religião como uma construção cultural, paisagem cultural, espaços públicos, literatura e música, percepção e significado, cinema, espaço de festas populares, território, imaginário espacial, imagens, história e biografia, grupos étnicos, gênero e sexualidade e identidade territorial (ROSENDAHL, 2010).

[...] Surgem periódicos especializados, como o Géographie et Cultures, na França, criado por Paul Claval em 1992, e o Ecumene, na Inglaterra e nos Estados Unidos, em 1994, posteriormente redenominado de Cultural Geographies. Ambos se juntam ao Journal of Cultural Geography criado nos Estados Unidos. A criação posterior do Social and Cultural Geography ampliou as possibilidades de publicação de textos relacionados à geografia cultural. (CORRÊA, 2009, p. 2)

Corrêa e Rosendahl (2005) afirmam que o esforço em estimular a área cultural no Brasil vem de várias frentes, a princípio da heterogeneidade cultural do país, da vitalidade, da criatividade dos geógrafos brasileiros e, por fim, das relações entre profissionais estadunidenses e europeus que se puseram a incentivar e inspirar o estudo da dimensão cultural do espaço.

\footnotetext{
${ }^{11}$ Núcleos de expressividade nacional: o primeiro foi criado em 1993, pela professora doutora ZenyRosendahl, no Departamento de Geografia da Universidade Estadual do Rio de Janeiro; atualmente é coordenado pela professora doutora Mariana Lamego. O segundo núcleo foi fundado pelo professor doutor Sylvio Fausto Gil Filho em 2003, na Universidade Federal do Paraná.
} 
Esse incentivo originou na produção da geografia da religião brasileira ${ }^{12}$, que tem como destaque alguns estudiosos. Zeny Rosendahl é um dos grandes nomes que, juntamente com Roberto Lobato Azevedo Corrêa, contribuíram para o desenvolvimento da produção cultural na geografia. Rosendahl publicou em 1996 a obra ${ }^{13}$ "Espaço e religião uma abordagem geográfica". A partir dela são gerados conceitos e princípios dentro do campo da geografia da religião. O primeiro é do espaço sagrado, explicado pela inter-relação entre ponto fixo e entorno, e juntamente com outros conceitos geográficos é lançada a concepção de espaço profano. Os demais temas propostos foram: fé, espaço e tempo-difusão e área de abrangência; os centros de convergência e irradiação religiosa; território e territorialidade; e lugar sagrado vivência, percepção e simbolismo.

Um segundo tema apresentado em 2009 foi "Hierópolis: o sagrado e o urbano", que contribuiu para desvendar as múltiplas funcionalidades urbanas, indicando com clareza a natureza simbólica, sagrada de uma construção humana. Destaca-se que a análise do estudo sobre espaço e religião traz consigo a concepção ontológica do filósofo das religiões, historiador e sociólogo Mircea Eliade, o qual trouxe para a geografia da religião a compreensão e a distinção conceitual sobre o sagrado e o profano.

A geografia da religião é interpretada segundo processos dinâmicos que ocorrem entre os grupos sociais em espaços diversos. Portanto, seu estudo representa inúmeras possibilidades de enxergar as influências religiosas no espaço. Diante do exposto, Rosendahl aponta um norte para as novas perspectivas de estudo:

A pesquisa geográfica sobre a religião produzida nos últimos dez anos enfatiza a perspectiva cultural, na qual são ressaltados dois pontos centrais: o sagrado e o profano. Parece necessário dar continuidade a essa perspectiva, aprofundando, porém, a análise das dimensões econômicas, políticas e do lugar, que relacione o sagrado e o profano à sociedade e ao espaço. (ROSENDAHL, 2011, p. 185)

Na geografia da religião brasileira também se destaca o professor Sylvio Fausto Gil Filho, com diversas publicações. A produção que aglutinou sua compreensão sobre a dimensão do sagrado no espaço foi intitulada de "Espaços sagrados: estudo em geografia da religião". A partir dela são explicados conceitos de poder, representações e o sagrado como formas simbólicas. Na geografia se traduz em espaços de representações e da territorialidade do sagrado. À luz dessa teoria foram colocadas três realidades religiosas diferentes: o estudo do cristianismo católico romano, do islã shi'i e da peregrinação bahá 'inas cidades de Haifa e Akká.

Esses são os principais centros de influência e pesquisa atuantes na área da geografia cultural no Brasil, a qual abrange temas culturais para além da religião. A partir desses é que teoria e conhecimento vêm sendo disseminados, fomentando o despertar das novas possibilidades de compreender o espaço, bem como o acréscimo da produtividade acadêmica segundo o olhar heterogêneo nas temáticas encontradas pelos geógrafos brasileiros.

\footnotetext{
${ }^{12} \mathrm{~A}$ pesquisa vanguarda no âmbito geográfico religioso intitula-se "Pequenos centros paulistas de função religiosa",realizada por Maria Cecília França no ano de 1972, apresentada para título de doutoramento na USP. Tal tese é influenciada pela perspectiva do impacto religioso sobre a paisagem.

${ }^{13} \mathrm{~A}$ obra de Rosendahl representa o firmamento entre ideologias geográficas e não geográficas, a exemplo da filosofia das religiões deMirceaEliade.
} 


\section{Últimas palavras}

O desenvolver das análises da religião enquanto tema cultural de importância geográfica mostra que a pesquisa desse campo disciplinar vai além de apontar um fenômeno particular, pois apresenta uma proposta de relações aproximadas, a partir da qual são percebidos os valores simbólicos, aspectos culturais e de resistências impregnados nos discursos, nos espaços, territórios, paisagens entre outros por meio das relações reais que esses indivíduos têm com o "meio" que os transformam. Segundo Rosendahl (2010, p.12), [...] o entendimento do espaço não passa apenas pelas reflexões das leis econômicas, da política e dos conflitos de classe, mas também pela ideia de que a cultura tem uma dimensão espacial e temporal, manifestando-se de modo material e imaterial.

Esse artigo remontou sucintamente os caminhos que a geografia cultural percorreu, desde as influências naturalistas e positivistas ao materialismo histórico dialético da fenomenologia. Apresentou grandes nomes que contribuíram para a ciência geográfica, enriquecendo-a a partir de incursões significativas para o eixo espaço e religião.

Expõe claramente que há séculos uma gama de autores se dispõe a discutir e produzir conhecimento sobre a temática por prismas distintos, frente à realidade de cada período. Esses estudos têm amplas proporções e características diversas em níveis de aprofundamentos múltiplos, uma vez que na perspectiva tempo-espaço as mudanças ocorridas no campo cultural produzem um dinamismo longe da estagnação, o qual é responsável pelo enriquecimento histórico da temática.

Por fim, o artigo trouxe consigo um ar retrospecto, intencional. A partir do seu conteúdo é possível remontar a base conceitualhistórica do pensamento geográfico para a produção atual de conhecimento sobre qualquer tema da geografia cultural, independente da escolha do eixo de investigação, bem como das escolhas de pares interdisciplinares para o norteamento e aprofundamento dos estudos. Além disso, sua formulação reforça de maneira construtiva a importância de considerar as dimensõesculturais para o estudo da geografia.

\section{Referências}

BERGER, PeterLudwig. O dossel sagrado: elementos para uma teoria sociológica da religião. São Paulo: Editora Paulina, 1985.

CLAVAL. Paul. A geografia cultural. Florianópolis: editora da UFSC, 1999.

."A volta do cultural" na geografia. Mercator- Revistade Geografia da UFC, ano 01, $\overline{\mathrm{n}^{\mathrm{o}} 1, \mathrm{p} .19-28,2002 .}$ dez. 2011.

Geografia cultural: um balanço. Revista Geografia: Londrina, v. 20, n⿳3 3 , p.005-024, .Epistemologia da geografia. Florianópolis: editora da UFSC, 2011.

A contribuição francesa ao desenvolvimento da abordagem cultural na geografia. In: CORREAA, Roberto Lobato e ROSENDAHL, Zeny (Org.). Introdução à geografia cultural. Rio de Janeiro: Bertrand Brasil, 2011, p.147-186.

CORRÊA, Roberto Lobato. Sobre a geografia cultural. Instituto Histórico Geográfico do Rio Grande do Sul, Porto Alegre, p.1-9, nov. 2009. 
.A geografia cultural e o urbano. In: CORRÊA, Roberto Lobato e ROSENDAHL, Zeny (Org.). Introdução à geografia cultural. Rio de Janeiro: Bertrand Brasil, 2011, p. 167 186.

Carl Sauer e Denis Cosgrove: a paisagem e o passado. Espaço Aberto, Rio de Janeiro, V. 4, nº 1, p. 37-46, maio2014.

Sobre Carl Sauer: uma introdução. In: CORRÊA, Roberto Lobato e ROSENDAHL, Zeny(Org.). Sobre Carl Sauer. Rio de Janeiro: EdUERJ, 2011, p.11-20.

.Geografia cultural: apresentando uma antologia In: CORREAA, Roberto Lobato e ROSENDAHL,Zeny(Org.). Geografia cultural: uma ontologia. Rio de Janeiro: EdUERJ, 2012, p. 7-14.

CORRÊA, Roberto Lobato e ROSENDAHL, Zeny. Geografia cultural: introduzindo a temática, os textos e uma agenda. In: CORREAA, Roberto Lobato e ROSENDAHL, Zeny(Org.). Introdução à geografia cultural. Rio de Janeiro: Bertrand Brasil, 2011, p.9-18.

COSGROVE, Denis E. JACKSON, Peter. Novos rumos da geografia cultural. In: CORRÊA, Roberto Lobato e ROSENDAHL, Zeny (Org.).Introdução à geografia cultural.Rio de Janeiro: Bertrand Brasil, 2011, p. 135-146.

DUNCAN, James S. O supraorgânico na geografia cultural americana. Espaço e Cultura NEPEC, Rio de Janeiro, nº 13, p. 7-33, 2002.

O supraorgânico na geografia cultural americana. In: CORRÊA, Roberto Lobato e ROSENDAHL (Org.). Introdução à geografia cultural. Rio de Janeiro: Bertrand Brasil, 2011, p. 63-102.

DURKHEIM, Émile. As formas elementares da vida religiosa: o sistema totêmico na Austrália. São Paulo: Editora Martins Fontes, 2000.

ELIADE, Mircea. O sagrado e o profano: a essência das religiões. São Paulo: Editora Martins Fontes, 1992.

FICKELER, Paul. Questões fundamentais na geografia da religião. Espaço e Cultura - Edição Comemorativa (1993-2008), Rio de Janeiro: UERJ-NEPEC, 2008, p.7-35.

GADE, Daniel. Carl Sauer e a força da curiosidade nas pesquisas geográficas. In: CORREAA, Roberto Lobato e ROSENDAHL, Zeny (Org.). Sobre Carl Sauer. Rio de Janeiro: EdUERJ, 2011, p.21-38.

GEERTZ, Clifford. A interpretação das culturas. Rio de Janeiro:Editora LTC, 2008.

GIL, Filho Sylvio Fausto.Espaço sagrado: estudo em geografia da religião. Curitiba: Editora IBPEX, 2012.

HOLZER,Werther. A geografia humanista: uma revisão. In: CORRÊA, Roberto Lobato e ROSENDAHL, Zeny. Geografia cultural uma ontologia. Rio de Janeiro: EdUERJ, 2012, p. $165-177$. 
MOREIRA, Ruy. As transformações da geografia clássica. São Paulo: Editora Contexto, 2008.

ROSENDAHL, Zeny. Espaço e religião: uma abordagem geográfica. Rio de Janeiro: Editora UERJ-NEPEC, 1996.

Espaço e religião: uma abordagem geográfica. In: Mendonça, F.Kozel, S. Elementos de epistemologia da geografia contemporânea. Curitiba: UFPR, 2002.

Construindo a geografia da religião no Brasil. Espaço e Cultura - NEPEC, Rio de Janeiro, $n^{\circ} 15$, p. 1-13, 2003.

. Conferência NEPEC: local onde fluem as ideias e se escreve sobre elas. In: ROSENDAHL, Zeny (Org.). Trilhas do sagrado. Rio de Janeiro: EdUERJ, 2010, p.11-34.

Espaço cultura e religião: dimensões de análise. In: CORRÊA, Roberto Lobato e ROSENDAHL, Zeny. Introdução à geografia cultural. Rio de Janeiro: Bertrand Brasil, 2011, p. 187-224.

SAUER, Carl. O. Geografia cultural. In: CORREAA, Roberto Lobato e ROSENDAHL, Zeny. Introdução à geografia cultural. Rio de Janeiro: Bertrand Brasil, 2011, p. 19-26.

. Desenvolvimentos recentes em geografia cultural. In: CORRÊA, Roberto Lobato e ROSENDAHL, Zeny. Geografia cultural uma ontologia. Rio de Janeiro: EdUERJ, 2012, p. 43-86.

SPETH, W. W. Historicismo: a visão disciplinaria de mundo de Carl Sauer. In: Geografia cultural. In: CORREAA, Roberto Lobato e ROSENDAHL, Zeny. Sobre Carl Sauer. Rio de Janeiro: EdUERJ, 2011, p.35-96.

WAGNER, Philip. L. MIKESELL, Marvin. W. Os temas da geografia cultural. In: CORRÊA, Roberto Lobato e ROSENDAHL, Zeny. Introdução à geografia cultural. Rio de Janeiro: Bertrand Brasil, 2011, p.27-61. 